\title{
Tarnished gold: sixty years of antimicrobial drug use and misuse
}

Certain antimicrobial drugs-quinine and a few herbal anthelminthics-have been around for centuries. Hexamine (methenamine) for urinary infections and arsphenamine (Salvarsan) for syphilis were developed in the late 19 th and early 20 th century, respectively, and a handful of antiparasitic drugs appeared between the two World Wars, largely as a result of efforts in the German dyestuffs industry, which was then expanding into pharmaceuticals. ${ }^{1}$ However, truly effective drugs for the treatment of life-threatening bacterial infections have been available for just 60 years: the original report of Gerhard Domagk's Prontosil (in effect, the first sulphonamide) appeared in German in February 1935, ${ }^{2}$ while the first description in English was a transcript of an address by Heinrich Hörlein to an audience at the Royal Society of Medicine in London on October 3rd of the same year. ${ }^{3,4}$ Penicillin, of course, followed in the early 1940s and the rest, as they say, is history.

From the first, resistance to the new antibacterial agents announced itself as a potential problem. Sulphonamide resistance was evident through in-vitro testing and animal experiments at an early stage. ${ }^{5}$ The discovery that micro-organisms could produce an enzyme that destroyed penicillin was made almost as soon as the therapeutic potential of the drug itself was realised. ${ }^{6}$ All subsequent compounds have brought greater or less problems of resistance in their train and no systemic antimicrobial agent has yet been discovered that has proved to be beyond the ingenuity of micro-organisms to outwit. Moreover, advances in microbial chemistry, physiology and genetics that have paralleled the development of antibacterial drugs have revealed an astonishing versatility, not only in the ways in which the microbes can avoid or overcome the antimicrobial assault, but also in their capacity to share and disseminate that ability among their kind.

For the past 60 years these life-saving drugs have been used with unrestrained enthusiasm far surpassing the needs of the management and control of infection. We tend to forget that infected patients commonly recovered from their infections before antimicrobial agents became available, for reasons that are not difficult to find. The complex defence mechanisms of the host, not least the highly sophisticated immunological surveillance system, complete with rapid reaction force, has been evolving for as long as mankind itself: indeed, for millions of years. Setting aside diseases like tuberculosis and leprosy, in which the immune system is subverted, or bacterial endocarditis, in which the infection is inaccessible, antimicrobial agents ordinarily play only a supplementary role in controlling the infection, often simply by holding the position (bacteriostatic agents) while the defences are effectively mobilised. Practically all chemotherapy, except in severely immunodepleted and grossly neutropenic patients, is combination therapy - the drug acting alongside the host defences, give or take a few interactions that may render the combination less, or more, effective.

Antibiotic resistance has come under the microscope many times in the past $\mathbf{4 0}$ years. A Ciba Foundation Symposium was devoted to the topic as early as $1957 ;^{7}$ in 1981, a group of 150 scientists from 25 countries issued a statement drawing attention to the public health concerns arising from the dissemination of antibiotic resistance traits. ${ }^{8}$ Prophesies of doom are published at regular intervals ${ }^{9,10}$ and at least one author invites us to contemplate the prospect of a postantimicrobial era. ${ }^{11}$

Are things really so bad? At present, no. Excessive use and, often, blatant misuse of antimicrobial agents has undoubtedly led to the emergence of resistance in bacteria all over the world, but up to now most infection that requires antimicrobial intervention remains amenable to the common antibiotics that have become the mainstay of the formulary for the treatment of infectious disease. Moreover, when multiresistant organisms have threatened to take over, chiefly in institutions with serious resistance problems, the coincident proliferation of new (though inevitably more expensive) agents has, until now, prevented the problem from reaching unmanageable proportions. The trouble is that this situation is unlikely to persist. Already, the pharmaceutical industry is losing interest in the vastly expensive process of developing new antibacterial drugs for a crowded and uncertain market. Such new compounds as will appear are unlikely to be affordable by the great majority of those who need them most.

What, then, are the solutions? To answer this it is first necessary to recognise that there are two problems not one: the problem of resistance in hospitals, and the global problem of resistance in the community. In hospitals, the type of drug resistance that causes the greatest concern is exhibited principally by opportunist pathogens, including staphylococci, enterococci and various gram-negative rods, that threaten vulnerable patients, principally in high-dependency units. Such resistance is difficult to control, but can be 
successfully countered by the triple approach of careful, informed prescribing; adherence to agreed policies of drug usage; and the strict application of control of infection measures. Here, the solution (or, at least, mitigation of the problem) is in the hands of the individual prescriber, the institution and the infection control team, who all need to collaborate closely in the interests of the patients they serve.

The global problem of resistance in the community is quite different. Here the micro-organisms associated with major problems of resistance are the classic pathogens, including mycobacteria, pneumococci, gonococci, salmonellae (particularly invasive species) and shigellae. The most serious effects of resistance in these organisms are suffered in economically disadvantaged countries where the general standards of drug manufacture, distribution and usage often fall below those of countries of the industrially developed world. In these circumstances, the solution is not entirely in the hands of the prescriber, since the problem is one of drug regulation which must be addressed at governmental level. As Calvin Kunin has forcefully and cogently argued, solutions to these problems can be achieved only through international co-operation between governments, the pharmaceutical industry, health care providers and consumers. ${ }^{12}$

\section{References}

1. Greenwood D. Conflicts of interest: the genesis of synthetic antimalarial agents in peace and war. $J$ Antimicrob Chemother (in press).

2. Domagk G. Ein Beitrag zur Chemotherapie der bakteriellen Infektionen. Dtsch Med Wochenschr 1935; 61 : 250-253.

3. Horlein H. The chemotherapy of infectious diseases caused by protozoa and bacteria. Proc $R$ Soc Med 1936; 29: 313-324.

4. Anonymous. Chemotherapy in streptococcal infections. Lancet $1935: 2: 840$

5. Maclean IH, Rogers KB, Fleming A. M. \& B. 693 and pneumococci. Lancet 1939; 1 : 562-568.

6. Abraham EP. Chain E. An enzyme from bacteria able to destroy penicillin. Nature 1940: 146: 837 .
Wherever and whenever bacteria are subjected to the selective pressure of antibiotic use, they will respond by exhibiting resistance in some form or other. Conversely, there is no necessity for bacteria to carry the extra luggage of resistance genes if the selective advantage conferred by the mechanisms that they encode is removed. In serious infection - even in trivial infection if the circumstances justify it-antibiotics must plainly be used. Usage, however, must be rational and judicious. In no other form of prescribing does administration of the drug have implications beyond the needs of the individual patient. Antimicrobial agents are a relatively new and precious resource; in the 60 years that effective antibacterial agents have been available they have transformed the lives of countless numbers of persons suffering from infectious diseases. If they are to retain their value, we must simply learn to use them wisely, inside and outside hospital, while there is still time to reverse present trends.

D. GREENWOOD Division of Microbiology, Department of Clinical Laboratory Sciences, University Hospital, Queen's Medical Centre, Nottingham NG7 2UH

7. Wolstenholme GEW, O'Connor CM (eds). Drug resistance in micro-organisms. London, J and A Churchill. 1957.

8. Anonymous. Saving antibiotics from themselves. Nature 1981; 292: 661 .

9. Neu HC. The crisis in antibiotic resistance. Science 1992; 257 . 1064-1073.

10. Murray BE. Can antibiotic resistance be controlled? $N$ Engl $J$ Med 1994; 330 : 1229-1230.

11. Cohen ML. Epidemiology of drug resistance: implications for a post-antimicrobial era. Science 1992; 257: 10501055 .

12. Kunin CM. Resistance to antimicrobial drugs-a worldwide calamity. Ann Intern Med 1993; 118: 557-561. 